\title{
Analysis of the disparity factor of the Net Asset Value (NAV) on the Exchange Trade Fund (ETF) and its market price on the Indonesia Stock Exchange (IDX)
}

\author{
A. Rahmanto \& B. Wibowo \\ Master of Management, University of Indonesia, Jakarta, Indonesia
}

\begin{abstract}
Efficient market hypothesis (EMH) explains that the price of a security will always be traded at its fair price. However, this is not the case for ETFs, where mispricing can occur. This research analyzes the disparity factors that can affect mispricing of 42 ETFs on IDX using secondary data. This research uses the ordinary least squares (OLS) regression method with the research hypothesis that disparity factors including the fund age, volume, difference between high and low prices, and IHSG return influence mispricing of ETFs. The result of this research indicates that only three factors (without IHSG return) have significant effects on ETF mispricing with R squared about $3.13 \%$, which is similar to that reported in previous research studies by Atanasova and Weisskopf (2020) and by Shin and Soydemir (2010). The aim of this research is to help investors, investment managers, and dealers invest in and develop ETFs in Indonesia.
\end{abstract}

\section{INTRODUCTION}

In Indonesia, according to Zulfikar (2016), the first ETF was implemented in Indonesia at the end of 2007. Until 2011, only a few investors knew about ETFs in Indonesia. At the time of this research, in mid-2020, the ETFs in Indonesia showed an increase in their number. There were 45 ETFs listed on the Indonesia Stock Exchange (IDX), but only 42 ETFs were with the underlying asset of stock. Theoretically, the net asset value (NAV) of an ETF should be no different from its market price based on the efficient market hypothesis (EMH). However, some ETF studies have found mispricing of ETFs. Looking at the many ETFs that are listed on the IDX but still have limited enthusiasts investing in them, this research will examine the following question: "what are the disparity factors that affect mispricing of ETFs on the IDX?"

\section{LITERATURE REVIEW}

There are some previous studies discussing topics related to mispricing between ETF and NAV market prices that have been carried out with different data and results.

Engle and Sarkar (2006) showed that the premium (discount) for domestic ETFs is generally small and temporary, and the standard deviation is smaller than the bid-ask spread. They used the Kalman Filter Space model, dyna model, GARCH model, and error-in-variables model. For the data, they used 21 domestic and 16 international ETFs, both daily and intraday, during the period of April 2000 to September 2000. The result for international ETFs shows that the premium (discount) is much bigger and lasts for up to several days. This difference is due to a higher cost of creation and redemption, and the bid-ask spread is wider.

Petajisto (2017) analyzed inefficiencies in the pricing of ETFs using time series and equal value-weighted of volatility, cross-sectional dispersion, \& volatility, and t-statistics with daily data at the American ETF market from early 2007 until the end of 2014. The result shows a new approach to detect mispricing in ETFs by measuring it in relation to the market price of a peer 
group that will eliminate the old NAV problems. This approach reduces the premium effect on both international holders and liquidity, but it still fluctuates between 100 and $200 \mathrm{bps}$. This test confirms that the creation of an active trading strategy aims for the exploitation of mispricing because the strategy creates significant profits before the transaction costs are highly statistically significant. Atanasova and Weisskopf (2020) analyzed the relationship between ETF premium (discount) and market liquidity using the premium and illiquidity ETF regression model, GMM, PVAR model, VAR Granger causality, Wald test, and P test statistic. For the data, they used 584 daily international ETFs from early 2012 until the end of 2017. The result shows that a lower ETF liquidity leads to a large price difference between the ETF price and the value of the underlying securities. The effect remains significant after controlling for the characteristics of the ETF, holding cost, and overall macroeconomic conditions.

\section{METHODOLOGY}

\subsection{Sample design}

In analyzing ETF mispricing, this paper uses the Eviews 9 and the ordinary least square (OLS) model. This research uses data stream sourced from Thomson Reuters Eikon, historical data from 42 ETFs listed on the IDX, and IHSG return with a daily retrieval period that started from the beginning of each ETF established until September 2020. Data taken by ETFs with its underlying asset type in the form of shares includes NAV and market price of the ETF at the daily closing on the IDX, some trading data for each ETF such as volume, and the difference between high and low prices. The number of data observations used in this research was 12,894.

The variables used in this research consist of dependent and independent variables. The dependent variable is the ratio of the price-NAV difference over its NAV (ETF mispricing ratio). The independent variables are fund age (age of ETF since it began trading on the IDX), volume (number of trading transactions in an ETF on the IDX), difference between high and low prices, (difference between the highest and lowest prices on a trading day), and IHSG return (daily return of the IHSG index). In this research, some variables, namely, ETF mispricing ratio and fund age, need to be processed first.

\subsection{Model specification}

This research began by calculating and looking for the formation of descriptive data from the mispricing of 42 ETFs in Indonesia on the annual period category from 2014 to 2020 because the growth of ETFs started around these years. This category was divided based on the ETF mispricing ratio when above $0 \%$ (premium) and below $0 \%$ (discount) to indicate the position of ETF mispricing observation. At this initial stage, it was intended to describe the mispricing conditions for ETFs on the IDX. The first step was calculating the ETF mispricing ratio as follows:

$$
\text { ETF mispricing }_{\mathrm{f}, \mathrm{t}}=\frac{p_{f, t}-N A V_{f, t}}{N A V_{f, t}}
$$

where ETF $_{\text {mispricing }}, t$ is the ratio of the price-NAV difference over its NAV; $P_{f, t}$ is the market price of an ETF $f$ at time $\mathrm{t}$; and $N A V_{f, t}$ is the NAV of an ETF $\mathrm{f}$ at time $\mathrm{t}$.

The next step was to calculate the fund age, starting from the beginning of the marketed ETF until the last day of trading in September 2020. The formula for the calculation is as follows:

$$
\text { Fund Age }_{f, t}=\text { Date Observation }, t-\text { Date Established } \text { ETF }_{f}
$$

where Age $_{f, t}$ is the age of an ETF $\mathrm{f}$ at time $\mathrm{t}$; Date Observation $_{f, t}$ is the date of observation of an ETF $\mathrm{f}$ at time t; and Date Established $E_{T F}$ is the established date of an ETF $\mathrm{f}$. 
After obtaining the processed variable data, the variables were tested to determine the factors that resulted in ETF mispricing using the OLS model. In previous research, Atanasova and Weisskopf (2020) and Shin and Soydemir (2010) used the OLS regression model with panel data. Yet, in this research, due to limited data and unbalanced ETF trading time, the OLS regression model was applied using the cross-sectional data type of 42 ETFs. The following is the regression model and the assignment of variables to Eviews.

$$
|P D|_{f, t}=\alpha_{f}+\beta_{f 1} F U N D \_A G E_{f, t}+\beta_{f 2} V O L U M E_{f, t}+\beta_{f 3} \Delta H L_{f, t}+\beta_{f 4} I H S G_{f, t}+\varepsilon_{f, t}
$$

where $|P D|_{f, t}$ is the absolute value of ETF mispricing $_{f, t}$ or the absolute value of the ETF market price at time $\mathrm{t}$ over its NAV minus one; $F U N D \_A G E_{f, t}$ is the age of ETF $\mathrm{f}$ at time $\mathrm{t}$; VOLUME $E_{f, t}$ is the transaction volume of ETF $\mathrm{f}$ at time $\mathrm{t} ; \Delta H L_{f, t}$ is the difference between the high and low price of the ETF $\mathrm{f}$ at time $\mathrm{t}$; and $I H S G_{f, t}$ is the return of the IHSG index at time t.

\section{RESULTS}

Based on the annual period category from 2014 to 2020 , the calculation of observation data from 42 ETFs, which had the underlying asset of stock, shows that each ETF has an indication of mispricing each year. This finding is shown below in Table 1 .

Table 1. ETF mispricing ratio per year.

\begin{tabular}{lccccccc}
\hline & \multicolumn{7}{l}{ Number of ETF Per Year } \\
\cline { 2 - 9 } & 7 ETF & 8 ETF & 9 ETF & 12 ETF & 22 ETF & 35 ETF & 42 ETF \\
\hline Mispricing ETF Ratio & 2014 & 2015 & 2016 & 2017 & 2018 & 2019 & 2020 \\
\hline Premium Observation & 504 & 747 & 795 & 673 & 1177 & 1442 & 2109 \\
Discount Observation & 441 & 344 & 384 & 322 & 589 & 878 & 1021 \\
Total of Data Observation & 945 & 1101 & 1179 & 995 & 1766 & 2320 & 3120 \\
Average Mispricing (\%) & 0.04 & 0.40 & 0.46 & 0.53 & 0.32 & 0.27 & 1.67 \\
Average Absolute Mispricing (\%) & 0.45 & 0.76 & 0.92 & 0.97 & 0.82 & 0.87 & 2.46 \\
\hline
\end{tabular}

Table 1 explains that every year, ETFs in Indonesia experience mispricing. Comparison of the number of observations of premium and discount from year to year shows that most of them experience the number of premium observations more than the number of discount observations. It is found that the mispricing range with the largest number of observations occurred in 2020, with 42 ETFs whose mispricing range of premium was between greater than $0.5 \%$ and less than $1 \%$. The average ETF mispricing in all annual periods shows a premium or positive value, and only in 2020, it had the largest total observations. This was because the number of ETFs had increased and reached 42 compared to the previous year.

The results of the regression model estimation from Table 2 show that only the fund age, volume, and difference of high and low prices variables have a significant effect on ETF mispricing. The result for the fund age variable also has a significant effect on the research of Atanasova and Weisskopf (2020). Based on the work by Hubbard et al. (2010), fund age describes the reputation of mutual funds in managing their portfolios. Because the majority of ETFs in Indonesia are under 5 years old, there are still few ETFs that have a reputation in managing their portfolios and allowing for ETF mispricing. The next variable, volume, has a significant effect on ETF mispricing based on research by Caginalp and DeSantis (2017). Using turnover in which there is a trading volume component, their research shows that there is a mispricing effect on ETF if there is a large number of ETF stock transactions. Because the ETF market in Indonesia is considered inefficient, it does not rule out the possibility of a large enough ETF volume transaction. Furthermore, the variable 
Table 2. Regression model result.

\begin{tabular}{ll}
\hline & $42 \mathrm{ETF}$ \\
\cline { 2 - 2 } Variable & Coefficient \\
\hline FUND_AGE & $-0.0017^{* * *}$ \\
VOLUME & $-2.06 \mathrm{E}-09^{*}$ \\
HL & $0.0007^{* * *}$ \\
IHSG & -0.064 \\
Constant & 0.0164 \\
$R^{2}$ & 0.0313 \\
F-stat & $104.26^{* * *}$ \\
Observations & 12,894 \\
\hline$*, * *$, and ${ }^{* * *}$ denote significance at $10 \%, 5 \%$, and $1 \%$ \\
levels, respectively.
\end{tabular}

difference of high and low prices also shows a significant effect on ETF mispricing. In the research study of Caginalp and DeSantis (2017), the variable difference between high and low prices was used as a component in the relative difference between high and low prices, which can affect ETF mispricing in terms of volatility. The last variable, IHSG return, does not show any influence on ETF mispricing. However, this finding is different from the research of Marshall, Nguyen, and Visaltanachoti (2013), where they found that the index return has an influence on ETF mispricing. This probably happens because the ETF market in Indonesia is still relatively new. Moreover, the ETF data in this research consist of active ETFs that do not fully follow or refer to an index. The result of R squared of this research is $3.13 \%$. This finding is similar to the research of Atanasova and Weisskopf (2020) and Shin and Soydemir (2010), where they got an R squared of around $6 \%-7 \%$. However, several variables and regression models used in this research are different from their research, which does not include the expense ratio, AUM, bid-ask spread, NAV momentum, and the volatility of each stock from the portfolio of an ETF.

\section{CONCLUSION}

ETFs in Indonesia are still a relatively new investment product, and there are not many volume transactions on the stock exchange. In this research, it is found that ETF investment instruments in the Indonesian ETF capital market still indicate inefficiencies in the market. With this mispricing, the ETF market in Indonesia shows inefficiency. This can be seen from the mispricing of every 42 ETF listed on trading days in the exchange market. Most of the mispricing of ETFs in Indonesia is premium or overvalued for the annual period category from 2014 to 2020. In this research, several mispricing factors, namely, fund age, daily trading volume, and the difference between the highest and lowest prices show significant results on mispricing of ETFs, while the IHSG return variable has no effect on ETF mispricing. However, the influence of this factor does not really describe the occurrence of the mispricing because it only produces an R squared of $3.13 \%$. These results are not much different from the research of Atanasova and Weisskopf (2020) and Shin and Soydemir (2010). The implication of this research is that 2020 was the right year for investors to invest in ETFs because in the future, ETFs will further grow in Indonesia, and profits are still being made from the mispricing condition of ETFs with a premium value.

\section{REFERENCES}

Atanasova, C. \& Weisskopf, J. P. 2020. The price of international equity ETFs: The role of relative liquidity. Journal of International Financial Markets, Institutions and Money 65. 
Shin, S. \& Soydemir, G. 2010. Exchange-traded funds, persistence in tracking errors and information dissemination. Journal of Multinational Financial Management 20: 214-234.

Zulfikar. 2016. Introduction to the capital market with a statistical approach. 1st ed. Yogyakarta: Deepublish. Engle, R. \& Sarkar, D. 2006. Premiums-Discounts and Exchange Traded Funds. The Journal of Derivatives 13: 27-45.

Petajisto, A. 2017. Inefficiencies in the pricing of exchange-traded funds. Financial Analysts Journal 73: 24.

Hubbard, R. G., Koehn, M. F., Ornstein, S. I., Van Audenrode, M. \& Royer, J. 2010. The mutual fund industry: Competition and investor welfare. New York: Columbia University Press.

Caginalp, G. \& Desantis, M. 2017. Does price efficiency increase with trading volume? Evidence of nonlinearity and power laws in ETFs. Physica A 467: 436-452.

Marshall, B. R., Nguyen, N. H. \& Visaltanachoti, N. 2013. ETF arbitrage: Intraday evidence.

Journal of Banking \& Finance 37: 3486-3498. 